\title{
Research Paper: Effects of Compassion-focused Therapy on Psychological Wellbeing, Life Expectancy, and Psychological Flexibility in Individuals With Human Immunodeficiency Virus
}

\author{
Farzane Khalaj $^{1}$, Behrooz Dolatshahi2 ${ }^{* *}$ (D, Fariborz Bagheri
}

1. Department of Psychology, Science and Research Branch, Islamic Azad University, Tehran, Iran.

2. Department of Clinical Psychology, University of Social Welfare and Rehabilitation Sciences, Tehran, Iran.

\begin{tabular}{|c|c|}
\hline $\begin{array}{l}\text { Use your device to scan } \\
\text { and read the article online }\end{array}$ & Citation: Khalaj, F., Dolatshahi, B., \& Bagheri, F. (2020). Effects of Compassion-focused Therapy on Psychological Wellbe- \\
\hline 口ifing & $\begin{array}{l}\text { ing, Life Expectancy, and Psychological Flexibility in Individuals With Human Immunodeficiency Virus. Journal of Practice in } \\
\text { Clinical Psychology, 8(4), 317-324. https://doi.org/10.32598/jpcp.8.4.726.1 }\end{array}$ \\
\hline arsin & dol' https://doi.org/10.32598/jpcp.8.4.726.1 \\
\hline
\end{tabular}

\section{(i) (3)}

Article info:

Received: 25 Apr 2020

Accepted: 10 Aug 2020

Available Online: 01 Oct 2020
Keywords:

Compassion, Wellbeing,

Hope, Flexibility, Human Immunodeficiency Virus

\section{ABSTRACT}

Objective: Human Immunodeficiency Virus (HIV) causes a debilitating disease that affects the involved patient's life. Therefore, investigating and introducing effective interventions to improve the status of these patients are among the necessities of modern research. This study aimed to investigate the effects of Compassion-focused Therapy (CFT) on enhancing psychological wellbeing, life expectancy, and psychological flexibility in HIV-infected patients.

Methods: This was a quasi-experimental study with a pre-test-post-test-follow-up and a control group design. The statistical population included all patients with an active file in the Tehran Blood Transfusion Organization who were eligible to participate in the study according to inclusion criteria. Thirty-four cases were selected by purposive sampling method and randomly assigned into two groups of CFT and control ( $n=17 /$ group). During the research process, 2 subjects from the experimental group and 2 subjects from the control group were removed. The study participants were assessed before, after, and three months after the intervention using the Ryff Psychological Well-being Questionnaire, Schneider's Hope Scale, and Bond's Psychological Flexibility Questionnaire. The obtained data were analyzed using repeated-measures Analysis of Variance (ANOVA) in SPSS.

Results: The present research findings suggested that psychological wellbeing ( $\mathrm{F}=112.83$, $\mathrm{P}=0.001)$ life expectancy $(\mathrm{F}=117.02, \mathrm{P}=0.001)$, and psychological flexibility $(\mathrm{F}=65.61$, $\mathrm{P}=0.001)$ significantly increased in the CFT group, compared to the controls $(\mathrm{P}>0.001)$.

Conclusion: The obtained data revealed that CFT was effective in increasing psychological wellbeing, life expectancy, and psychological flexibility in HIV-infected patients. 


\section{Highlights}

- Compassion-focused therapy effectively enhanced psychological wellbeing in HIV-infected patients.

- Compassion-focused therapy was effective in the improvement of life expectancy and psychological flexibility in HIV-infected patients.

- Compassion-focused therapy effectively improved psychological wellbeing, life expectancy, and psychological flexibility in patients with HIV.

\section{Plain Language Summary}

Acquired Immunodeficiency Syndrome (HIV) is a progressive and prevalent disease. Individuals receiving modern therapies have a longer lifespan, but dealing with the disease and its therapeutic side effects significantly impact their mental health. These patients need to receive psychotherapy. Therefore, it is necessary to evaluate the effectiveness of recent interventions on the psychological status of this group. In this study, the effectiveness of compassion-based therapy, which is one of the new therapies in psychotherapy approaches, was evaluated in patients with HIV. The relevant results suggested that this treatment improved mental health, psychological flexibility, and life expectancy in the study participants.

\section{Introduction}

pproximately 39 million individuals died due to Human Immunodeficiency Virus (HIV) infection, and $>40$ million people are currently living with HIV; 14000 new cases are infected by HIV per day (Eilami, Nazari, Dousti, Sayehmiri \& Ghasemi, 2019). The number of individuals who live with HIV/Acquired Immunodeficiency Syndrome (AIDS) has increased in recent years. This is because advanced therapies allow patients to live longer (Patton, 2015). Epidemiological studies in Iran revealed that the prevalence of HIV is different in various regions of the country, ranging from 8.1 per 100000 in the west, 5.1 in the north and center, one in the east, to 6.3 in the south. Currently, Iran has reached the HIV epidemic proportion and it is more prevalent among high-risk groups, such as prisoners, substancedependents, and sex workers (Joulaei, Lankarani, Kazerooni \& Marzban, 2017). People Who Live with HIV (PWLH), as a chronic and disabling disease, experience high levels of anxiety (Brandt et al., 2017), depression (Bhatia \& Munjal 2014), sleep disorders (Gamaldo et al., 2013), suicidal ideation (Ruffieux et al., 2019), impaired sexual function (Khuat et al., 2018), impairments in daily living activities, and socio-psychological pressures (Russell et al., 2016). There is no definitive cure for HIV; thus, patients accept the feelings of helplessness and inefficiency, instead of managing and controlling the disease. Accordingly, most of the PWLH report low life expec- tancy (Wandeler, Johnson, \& Egger, 2015). Decreased hope for biopsychological health puts individuals at risk (Heidari\& Ghodusi, 2015). Hope is a cognitive concept that focuses on the future. Hopeful individuals have a stronger immune system and present higher performance in controlling diseases (Sung et al., 2019).

Psychological wellbeing is another important concept in chronic conditions. The lack of a definitive treatment along with social stigma affects the psychological state of PWLH and make their psychological wellbeing vulnerable (Sun, Wu, Qu, Lu \& Wang, 2014). Studies reported that $44 \%-79 \%$ of PWLH suffer from some degree of anxiety and clinical depression (Sun et al., 2014; Betancur, Lins, Oliveira, \& Brites, 2017). Psychological flexibility is an ability that helps individuals to modify their thoughts and behaviors in response to various life changes in stressful situations (Asensio-Martínez et al., 2019). Psychological flexibility is more essential in chronic diseases, such as HIV, in which cognitive impairments are among their long-term complications (Alford et al., 2019). Additionally, psychological flexibility plays a protective role in chronic diseases (Rudnik, Piotrowicz, Basińska \& Rashedi, 2019); promoting psychological flexibility can increase individuals' adaptability to chronic diseases (Kuba \& Weissflog, 2017).

HIV profoundly affects mental health; thus, psychotherapists have developed various treatment plans to reduce the psychological symptoms of the disease and improve the Quality of Life (QoL) of patients (Sherr, 
Clucas, Harding, Sibley \& Catalan, 2011). This population always experience a sense of shame and guilt, and their self-esteem is at risk (Kalomo, 2018). According to previous evidence, Compassion-focused Therapy (CFT), as an effective psychological intervention for numerous disorders, can improve the secondary symptoms associated with the disease and even help with the biological treatment of the patients (Brion, Leary, \& Drabkin, 2014; Montero-Marínet al., 2018). Thus, CFT seems to be an appropriate option for patients with HIV, too (Eller et al., 2014). Neff (2003, 2005) defined self-compassion as a concept with 3 main elements, as follows: kindness against self-judgment, human commonalities against isolation, and the presence of mind in the face of extreme assimilation. Compassion increases psychological flexibility (Asensio-Martínez et al., 2019), hope (Wong, 2018), and psychological wellbeing (Wickland Gastin, 2017). Shahabi, Shahabi, and Foroozandeh (2019) reported that high self-compassion increases the psychological flexibility of couples. Karakasidou and Stalikas (2017) documented that self-compassion increases psychological wellbeing. Tara, Hobbs, Lorraine, and Arthur (2019) also stated that self-compassion presents positive effects on life expectancy. Despite the importance of the psychological consequences of HIV, no study has investigated the efficacy of CFT on increasing the life expectancy, psychological wellbeing, and psychological flexibility of PWLH. Therefore, the current study was conducted in response to this research gap.

\section{Methods}

This was a quasi-experimental study with a pre-test, post-test, follow-up and a control group design. The study population was all PWLH in Tehran City, Iran, with an active case in the Tehran Blood Transfusion Organization in 2019. Initially, according to the inclusion and exclusion criteria of the study, 60 participants were selected by convenience sampling approach. Then, based on Cohen's formula (alpha: $0.05 \&$ test power: $84 \%$ ), 34 participants were invited to participate in this study using a random sampling method. The inclusion criteria of the study were as follows: having an active file as an HIV-infected patient; being aged 18-45 years; not having psychiatric disorders; not taking psychiatric drugs; not having substance-dependence, and not receiving psychological treatment during the past 6 months. The exclusion criteria of the study were absence from $>2$ intervention sessions and taking any psychiatric medication. The Depression Anxiety Stress Scale (DASS-21) was used to homogenize the research population. In this case, the scores lower than the cut-off point of DASS-21 were used as the criteria of the patients without psychiatric disorders. By random sampling technique, 34 subjects were assigned to the CFT and control groups ( $\mathrm{n}=17$ /group). The research participants completed a demographic data questionnaire, the Ryff 18-item Wellbeing (PWB) Scale (1995), Schneider's Life Expectancy Scale (1999), and Bond Psychological Flexibility Questionnaire (PFQ, 2012) in pre- and post-intervention phases, as well as three months after the intervention (follow-up step). The study was of a double-blind design, as the investigator and participants were blind and only the first author who delivered the intervention was aware of the relevant data. The intervention group received eight 90-minute CFT sessions (based on Gilbert's protocol); however, the control group received no intervention. During the research process, 2 subjects from the experimental group and 2 control subjects were removed, due to unwillingness to continue the research. Eventually, the data obtained from 30 individuals were analyzed. In addition to descriptive statistical methods (mean, standard deviation, frequency, $\&$ percentage), collected data were analyzed by a blind analyzer, using repeated-measures Analysis of Variance (ANOVA) in SPSS.

\section{Results}

The current research data concerning the study groups' demographic characteristics suggested no significant different in terms of age $(\mathrm{t}=1.3, \mathrm{P}=0.19)$, educational level $\left(\mathrm{x}^{2}=0.38, \mathrm{P}=0.73\right)$, marital status $\left(\mathrm{x}^{2}=1.00, \mathrm{P}=0.31\right)$, and disease duration $(\mathrm{F}=0.59, \mathrm{P}=0.55)$ (Table 1$)$.

The Kolmogorov-Smirnov results indicated that the data distribution was normal and parametric tests can be used, accordingly $(>0.05)$. There was a significant difference between the post-test scores of the study groups in terms of all research variables $(\mathrm{P}<0.001)$; these differences were also significant in the follow-up stage $(\mathrm{P}<0.001)$ (Table 2). Besides, the post-test and follow-up mean values of the intervention groups were significantly higher than those of the control group (Table 3).

Based on the measured Eta-coefficients, the intervention enhanced the psychological wellbeing, life expectancy, and psychological flexibility of the intervention group by $38 \%, 22 \%$, and $37 \%$, respectively. To compare the pre-test, post-test, and follow-up data, the mean comparison test was used, which its results are presented in Table 4. There was a significant difference between post-test and follow-up scores in the intervention group; while supporting its effectiveness, its stability was approved in the follow-up stage (Table 5). 
Table 1. Comparing the demographic characteristics of the study groups

\begin{tabular}{|c|c|c|c|c|}
\hline \multirow{2}{*}{\multicolumn{2}{|c|}{ Demographic Variable }} & \multicolumn{2}{|c|}{$\mathbf{N}$} & \multirow{2}{*}{ Statistics } \\
\hline & & CFT Group & Control Group & \\
\hline \multirow{3}{*}{ Educational level } & Under diploma & 10 & 11 & \multirow{3}{*}{$\begin{aligned} \chi^{2} & =0.38 \\
P & =0.73\end{aligned}$} \\
\hline & Diploma, associate degree, BA. & 3 & 3 & \\
\hline & MA. and PhD. & 2 & 1 & \\
\hline \multirow{3}{*}{ Marital status } & Single & 11 & 10 & \multirow{3}{*}{$\begin{array}{l}\chi^{2}=1.00 \\
P=0.31\end{array}$} \\
\hline & Married & 2 & 4 & \\
\hline & Divorced & 2 & 1 & \\
\hline Age (y) & \multirow[b]{2}{*}{ Mean $\pm S D$} & $30.20 \pm 6.54$ & $33.13 \pm 5.50$ & $\begin{array}{c}t=1.3 \\
P=0.19\end{array}$ \\
\hline Disease duration (y) & & $2.06 \pm 0.96$ & $2.46 \pm 0.83$ & $\begin{array}{l}t=1.21 \\
P=0.23\end{array}$ \\
\hline
\end{tabular}

Table 2. Mean \pm SD scores of life expectancy, psychological wellbeing, and psychological flexibility

\begin{tabular}{ccccc}
\hline \multirow{2}{*}{ Variables } & Group & \multicolumn{3}{c}{ Mean \pm SD } \\
\cline { 3 - 5 } & & Pre-test & Post-test & Follow-up \\
\hline Life expectancy & CFT & $32.06 \pm 4.90$ & $40.26 \pm 3.73$ & $42.73 \pm 3.88$ \\
& Control & $34.26 \pm 3.32$ & $34.26 \pm 3.71$ & $34.60 \pm 3.85$ \\
\hline Psychological wellbeing & CFT & $40.93 \pm 7.79$ & $53.20 \pm 7.26$ & $54.93 \pm 7.08$ \\
& Control & $37.20 \pm 7.57$ & $38.73 \pm 7.53$ & $39.20 \pm 7.82$ \\
\hline Psychological flexibility & CFT & $18.80 \pm 2.33$ & $21.73 \pm 2.05$ & $23.13 \pm 2.13$ \\
& Control & $18.26 \pm 2.34$ & $17.73 \pm 2.31$ & $18.33 \pm 2.09$ \\
\hline
\end{tabular}

\section{Discussion}

The current study investigated the effectiveness of CFT on increasing psychological wellbeing, life expectancy, and psychological flexibility in PWLH. According to the achieved results, CFT could effectively improve psychological flexibility, psychological wellbeing, and life expectancy in the study participants. In line with the findings of the current study, Asensio-Martínez et al. (2018) concluded that CFT increases mental flexibility. In another study, Wong (2018) reported that compassion increases life expectancy. Besides, Wiklund Gustin (2017) reviewed various studies and concluded that compassion-based interventions improve the dimensions of psychological wellbeing. In justifying this finding, it can be mentioned that a basic principle of CFT is internalizing external thoughts, factors, images, and soothing behav- iors; through which, the mind will respond to internal elements, as external components. Therefore, the mind will be relaxed (Gilbert \& Irons, 2006). Individuals who are more passionate about themselves are less prone to be confused and depressed. In other words, compassion is an essential supportive factor to cope with anxiety and depression. When individuals feel unable to cope with life challenges, they become emotionally silent and feel scared and shy (Neff, 2003). Self-compassion is a healthy form of self-acceptance that reflects the degree of acceptance of undesirable aspects of life. McLean, Fiorillo, and Follette (2018), in a similar study, concluded that compassion-based exercises increase the flexibility of the mind. Skinta, Lezama, Wells, and Dilley, (2015) also reported similar results. As noted by Gilbert (2009), self-compassion increases emotional flexibility, because individuals can neutralize the threat system (i.e. 
Table 3. Comparing mean differences of the study groups

\begin{tabular}{|c|c|c|c|c|c|c|}
\hline & \multirow{2}{*}{ Group } & & \multicolumn{2}{|c|}{ Post-test } & \multicolumn{2}{|c|}{ Follow-up } \\
\hline & & & Mean Difference & $\mathbf{P}$ & Mean Difference & $\mathbf{P}$ \\
\hline \multirow{4}{*}{$\begin{array}{l}\text { Psychological } \\
\text { wellbeing }\end{array}$} & \multirow{3}{*}{ CFT } & Pre-test & -12.26 & $0.001^{*}$ & -14.00 & $0.001 *$ \\
\hline & & Post-test & -- & -- & -1.73 & $0.001 *$ \\
\hline & & Pre-test & -1.53 & 0.82 & -2.00 & 0.76 \\
\hline & Control & Post-test & -- & -- & -0.46 & 0.25 \\
\hline \multirow{4}{*}{ Life expectancy } & CFT & Pre-test & -8.20 & $0.001^{*}$ & -10.66 & $0.001 *$ \\
\hline & \multirow{3}{*}{ Control } & Post-test & -- & -- & -2.46 & $0.001 *$ \\
\hline & & Pre-test & 0.33 & 0.35 & 0.39 & 0.36 \\
\hline & & Post-test & -- & -- & 0.46 & 0.41 \\
\hline \multirow{4}{*}{$\begin{array}{l}\text { Psychological flex- } \\
\text { ibility }\end{array}$} & \multirow[t]{2}{*}{ CFT } & Pre-test & $-2.93^{*}$ & $0.001^{*}$ & -4.33 & $0.001 *$ \\
\hline & & Post-test & -- & -- & -1.40 & $0.001 *$ \\
\hline & \multirow[t]{2}{*}{ Control } & Pre-test & 0.53 & 0.37 & -0.067 & 0.99 \\
\hline & & Post-test & -- & -- & -0.60 & 0.24 \\
\hline
\end{tabular}

${ }^{*} \mathrm{P}<0.001$.

related to emotions, such as insecurity, defense, \& automatic stimulation) and activate the care system. This system is concerned with emotions, such as security, attachment, and the oxytocin addiction system. According to the literature, the higher the self-compassion, the lower the self-criticism, depression, anxiety, rumination, and depression.

Compassion is associated with increased happiness, optimism, personal initiative, and social communications (Neff, 2009); therefore, it may present positive impacts on psychological wellbeing, as an influential factor in

Table 4. The pre-test scores of repeated-measures ANOVA concerning life expectancy, psychological wellbeing, and psychological flexibility

\begin{tabular}{|c|c|c|c|c|c|c|c|}
\hline Variable & Source of Impact & Sum of Square Roots & df & Mean of Square Roots & $\mathbf{F}$ & $\mathbf{P}^{*}$ & Eta \\
\hline \multirow{3}{*}{$\begin{array}{l}\text { Psychological } \\
\text { wellbeing }\end{array}$} & Group & 2878.67 & 1 & 2878.67 & 17.74 & 0.001 & 0.38 \\
\hline & Stage & 960.00 & 1 & 960.00 & 200.59 & 0.001 & 0.87 \\
\hline & Stage $\times$ Group & 540.00 & 1 & 540.00 & 112.83 & 0.001 & 0.80 \\
\hline \multirow{3}{*}{$\begin{array}{l}\text { Life expec- } \\
\text { tancy }\end{array}$} & Stage & 453.75 & 1 & 453.75 & 200.60 & 0.001 & 0.87 \\
\hline & Stage $\times$ Group & 400.41 & 1 & 400.41 & 177.02 & 0.001 & 0.86 \\
\hline & Group & 356.01 & 1 & 356.01 & 8.26 & 0.008 & 0.22 \\
\hline \multirow{3}{*}{$\begin{array}{l}\text { Psychological } \\
\text { flexibility }\end{array}$} & Stage & 72.60 & 1 & 72.60 & 69.76 & 0.001 & 0.71 \\
\hline & Stage $\times$ Group & 68.62 & 1 & 68.62 & 65.61 & 0.001 & 0.70 \\
\hline & Group & 217.77 & 1 & 217.77 & 16.53 & 0.001 & 0.37 \\
\hline
\end{tabular}


Table 5. Comparing mean differences in post-test-follow-up stages

\begin{tabular}{|c|c|c|c|c|c|}
\hline \multirow{2}{*}{ Variable } & \multirow{2}{*}{ Stage } & \multicolumn{2}{|c|}{ Post-test } & \multicolumn{2}{|c|}{ Follow-up } \\
\hline & & Mean Difference & P* & Mean Difference & $\mathbf{P} *$ \\
\hline \multirow{3}{*}{$\begin{array}{l}\text { Psychological well- } \\
\text { being }\end{array}$} & Pre-test & 6.91 & 0.001 & 8.00 & 0.001 \\
\hline & Post-test & -- & -- & 1.13 & 0.001 \\
\hline & Post-test & -- & 0.001 & 1.40 & 0.001 \\
\hline Life expectancy & Pre-test & 4.10 & 0.001 & 5.50 & 0.001 \\
\hline \multirow{2}{*}{$\begin{array}{l}\text { Psychological flex- } \\
\text { ibility }\end{array}$} & Pre-test & 2.20 & 0.001 & 1.20 & 0.001 \\
\hline & Post-test & 1.00 & 0.001 & -- & 0.001 \\
\hline
\end{tabular}

HIV-positive patients. These processes enhance life expectancy and promote mental health. Furthermore, those who accept the disease and its living conditions adapt to their new conditions. Subsequently, by increasing selfcare behaviors, they feel more hopeful for survival.

The current study had limitations, including the small sample size, i.e. mainly due to difficulties in accessing the information of PWLH and their unwillingness to participate in the research. Another problem was the inability to conduct in-depth clinical interviews to assess patients' mental health, and only patients' scores on the stress, depression, and anxiety questionnaires were obtained. Besides, conducting a long-term follow-up was impossible, and patients with a long history of infection refused to participate in this study.

\section{Conclusion}

The present research findings revealed that CFT could improve psychological wellbeing, life expectancy, and psychological flexibility in individuals with HIV. We hope that our results help treatment agencies to design suitable programs addressing the HIV population.

\section{Ethical Considerations}

\section{Compliance with ethical guidelines}

All ethical principles were considered in this article. The study participants were informed about the purpose of the research and its implementation stages. They were also assured about the confidentiality of their provided information. Moreover, they could discontinue participation in the study whenever they wished. Eventually, if desired, the results of the research would be available to them. The present study is the result of a doctoral dissertation. The proposal of the study was approved by the Research Committee of the Science and Research Branch of Islamic Azad University, Tehran, Iran. An informed consent form was obtained from all individual participants included in the present study.

\section{Funding}

This article was extracted from the $\mathrm{PhD}$. dissertation of the first author at Department of Psychology, Science and Research Branch, Islamic Azad University, Tehran.

\section{Authors' contributions}

Methodology: Behrooz Dolatshahi and Farzane Khalaj; Writing the original draft: Behrooz Dolatshahi \& Farzane Khalaj; Writing, review, and editing: Fariborz Bagheri; Resources: Behrooz Dolatshahi \& Farzane Khalaj; Supervision: Behrooz Dolatshahi \& Fariborz Bagheri; Conceptualization, investigation, funding acquisition: All authors.

\section{Conflict of interest}

The authors declared no conflicts of interest.

\section{References}

Alford, K., Banerjee, S., Nixon, E., O'Brien, C., Pounds, O., \& Butler, A., et al. (2019). Assessment and management of HIVassociated cognitive impairment: Experience from a multidisciplinary memory service for people living with HIV. Brain Sciences, 9(2), 37-47. [DOI:10.3390/brainsci9020037]

Asensio-Martínez, Á., Oliván-Blázquez, B., Montero-Marín, J., Masluk, B., Fueyo-Díaz, R., \& Gascón-Santos, S., et al. (2019). Relation of the psychological constructs of resilience, mindfulness, and self-compassion on the perception of physical and mental health. Psychology Research and Behavior Management, 12(1), 1155. [DOI:10.2147/PRBM.S225169] 
Betancur, M. N., Lins, L., Oliveira, I. R. D., \& Brites, C. (2017). Quality of life, anxiety and depression in patients with HIV/HIV who present poor adherence to antiretroviral therapy: a cross-sectional study in Salvador, Brazil. Brazilian Journal of Infectious Diseases, 21(5), 507-14. [DOI:10.1016/j.bjid.2017.04.004]

Bhatia, M. S., \& Munjal, S. (2014). Prevalence of depression in people living with HIV/HIV undergoing ART and factors associated with it. Journal of clinical and diagnostic research: Indian Journal of Psychological Medicine. 39(6), 789-93. [DOI:10.4103/IJPSYM.IJPSYM_364_17]

Brandt, C., Zvolensky, M. J., Woods, S. P., Gonzalez, A., Safren, S. A., \& O'Cleirigh, C. M. (2017). Anxiety symptoms and disorders among adults living with HIV and HIV: A critical review and integrative synthesis of the empirical literature. Clinical Psychology Rreview, 51, 164-84. [DOI:10.1016/j.cpr.2016.11.005]

Brion, J. M., Leary, M. R., \& Drabkin, A. S. (2014). Self-compassion and reactions to serious illness: The case of HIV. Journal of Health Psychology, 19(2), 218-29. [DOI:10.1177/1359105312467391]

Eilami, O., Nazari, A., Dousti, M., Sayehmiri, F., \& Ghasemi, M. (2019). Investigation of HIV/ AIDS prevalence and associated risk factors among female sex workers from 2010 to 2017: A meta-analysis study. HIV/AIDS (Auckland, NZ), 11(1), 85-105. [DOI:10.2147/ HIV.S196085]

Eller, L. S., Rivero-Mendez, M., Voss, J., Chen, W. T., Chaiphibalsarisdi, P., \& lipinge, S., et al. (2014). Depressive symptoms, self-esteem, HIV symptom management self-efficacy and self-compassion in people living with HIV. HIV Care, 26(7), 795-803. [DOI:10.1 080/09540121.2013.841842]

Gamaldo, C. E., Spira, A. P.,Hock, R. S., Salas, R. E., McArthur, J. C., \& David, P. M., et al. (2013). Sleep, function and HIV: a multi-method assessment. HIV and Behavior, 17(8), 2808-15. [DOI:10.1007/ s10461-012-0401-0]

Gilbert, P., \& Procter, S. (2006). Compassionate mind training for people with high shame and self-criticism: Overview and pilot study of a group therapy approach. Clinical Psychology \& Psychotherapy: An International Journal of Theory \& Practice, 13(6), 353-79. [DOI:10.1002/cpp.507]

Gilbert, P. (2009). Introducing compassion-focused therapy. Advances in Psychiatric Treatment, 15(3), 199-2011. [DOI:10.1192/apt. bp.107.005264]

Heidari, M., \& Ghodusi, M. (2015). The relationship between body esteem and hope and mental health in breast cancer patients after mastectomy. Indian Journal of Palliative Care, 21(2), 198-202. [DOI:10.4103/0973-1075.156500]

Joulaei, H., Lankarani, K. B., Kazerooni, P. A., \& Marzban, M. (2017). Number of HIV-infected cases in Iran: true or just an iceberg. Indian Journal of Sexually Transmitted Diseases and AIDS, 38(2), 157-62. [DOI:10.4103/2589-0557.216984]

Kalomo, E. N. (2018). Associations between HIV-related stigma, selfesteem, social support, and depressive symptoms in Namibia. $A g$ ing $\mathcal{E}$ Mental Health, 22(12), 1570-6. [DOI:10.1080/13607863.2017. 1387763]

Karakasidou, E., \& Stalikas, A. (2017). The effectiveness of a pilot selfcompassion program on well being components. Psychology, 8(4), 538-49. [DOI:10.4236/psych.2017.84034]

Khuat, T. H., Do, T. T., Nguyen, V. A. T., Vu, X. T., Nguyen, P. T T., \& Tran, K., et al. (2018). The dark side of female HIV patient care: Sexual and reproductive health risks in pre-and post-clinical treatments. Journal of Clinical Medicine, 7(11), 402. [DOI:10.3390/ jcm7110402]

Kuba, K., \& Weissflog, G. (2017). Acceptance and commitment therapy in the treatment of chronic disease. Psychotherapie, Psychosomatik, medizinische Psychologie, 67(12), 525-36. [DOI:10.1055/s-0043-118742]

McLean, C. L., Fiorillo, D., \& Follette, V. M. (2018). Self-compassion and psychological flexibility in a treatment-seeking sample of women survivors of interpersonal violence. Violence and Victims, 33(3), 472-85. [DOI:10.1891/0886-6708.v33.i3.472]

Montero-Marín, J., Navarro-Gil, M., Puebla-Guedea, M., Luciano, J. V., Van Gordon, W., \& Shonin, E., et al. (2018). Efficacy of "attachment-based compassion therapy" in the treatment of fibromyalgia: A randomized controlled trial. Frontiers in Psychiatry, 8, 307. [DOI:10.3389/fpsyt.2017.00307]

Neff, K. D. (2003). Self-compassion: An alternative conceptualization of a healthy attitude toward oneself. Self and Identity, 2(1), 85-102. [DOI:10.1080/15298860309032]

Neff, K. D. (2005). Self-compassion: Moving beyond the pitfalls of a separate self-concept. Paper presented at the Quiet Ego Conference, Northern Arizona University, Flagsta. Link No Found

Neff, K. D. (2009). The role of self-compassion in development: A healthier way to relate to oneself. Human development, 52(4), 211-4. [DOI:10.1159/000215071]

Patton, L. L. (2015). Human Immunodeficiency Virus/Acquired Immune Deficiency Syndrome and Related Conditions. The ADA Practical Guide to Patients with Medical Conditions, 1(1), 231-57. [DOI:10.1002/9781119121039.ch11]

Rudnik, A., Piotrowicz, G., Basińska, M. A., \& Rashedi, V. (2019). The importance of cognitive flexibility and flexibility in coping with stress for the quality of life in inflammatory bowel disease patients during biological therapy. A preliminary report. Przeglad Gastroenterologiczny, 14(2), 121-8. [DOI:10.5114/pg.2018.81081]

Ruffieux, Y., Lemsalu, L., Aebi-Popp, K., Calmy, A., Cavassini, M., \& Fux, C. A., et al. (2019). Mortality from suicide among people living with HIV and the general Swiss population: 1988-2017. Journal of the International HIV Society, 22(8), 253-39. [DOI:10.1002/ jia2.25339]

Russell, S., Martin, F., Zalwango, F., Namukwaya, S., Nalugya, R., \& Muhumuza, R., et al. (2016). Finding meaning: HIV selfmanagement and wellbeing among people taking antiretroviral therapy in Uganda. PloS One, 11(1), 78-96. [DOI:10.1371/journal. pone.0147896]

Shahabi, B., Shahabi, R., \& Foroozandeh, E. (2019). Analysis of the self-compassion and cognitive flexibility with marital compatibility in parents of children with autism spectrum disorder. International Journal of Developmental Disabilities, 1(1), 1-7. [DOI:10.1080/2 0473869.2019.1573000

Sherr, L., Clucas, C., Harding, R., Sibley, E., \& Catalan, J. (2011). HIV and depression-a systematic review of interventions. Psychology Health, \& Medicine, 16(5), 493-527. [DOI:10.1080/13548506.2011.57 9990]

Skinta, M. D., Lezama, M., Wells, G., \& Dilley, J. W. (2015). Acceptance and compassion-based group therapy to reduce HIV stigma. Cognitive and Behavioral Practice, 22(4), 481-90 [DOI:10.1016/j.cbpra.2014.05.006 
Sun, W., Wu, M., Qu, P., Lu, C., \& Wang, L. (2014). Psychological well-being of people living with HIV/AIDS under the new epidemic characteristics in China and the risk factors: A population-based study. International Journal of Infectious Diseases, 28(1), 147-52. [DOI:10.1016/j.ijid.2014.07.010]

Sung, K. M., Yu, M., Kang, Y. S., Gu, M. O., Jung, M. S., \& Eun, Y., et al. (2019). The effects of a tripod approach for cancer patients on illness stress, health-promoting lifestyle, hope, and resilience. Cancer Nursing, 1(1), 746-52. [DOI:10.1097/ NCC.00000000000000746]

Tara, M., Hobbs, M. A., Lorraine, M., \& Arthur, K. C. (2019). The role of compassion and mindfulness in building parental resilience when caring for children with chronic illness or disability: A conceptual model. Frontiers in Psychology, 10(1), 1602. [DOI:10.3389/fpsyg.2019.01602]

Wandeler, G., Johnson, L. F., \& Egger, M. (2016). Trends in life expectancy of HIV-positive adults on ART across the globe: comparisons with general population. Current Opinion in HIV and AIDS, 11(5), 492-500. [DOI:10.1097/COH.0000000000000298]

Wiklund Gustin, L. (2017). Compassion for self and others as key aspects of well-being in changing times. Scandinavian Journal of Caring Sciences, 31(3), 427-33. [DOI:10.1111/scs.12536]

Wong, N. W. (2018). The role of hope, compassion, and uncertainty in physicians' reluctance to initiate palliative care. AMA Journal of Ethics, 20(8), 782-6. [DOI:10.1001/amajethics.2018.782] 